Table 1. comparison of the characteristics of SMA and IMA between SSc patients and $\mathrm{HC}$.

\begin{tabular}{|c|c|c|c|c|c|c|}
\hline \multirow[b]{2}{*}{ SMA } & \multicolumn{2}{|r|}{ SSc } & \multicolumn{2}{|r|}{$\mathrm{HC}$} & \multirow[b]{2}{*}{ p-value } & \multirow{2}{*}{$\begin{array}{c}\text { Age } \\
\text { adjusted } \\
\text { p-value }\end{array}$} \\
\hline & $\mathrm{N}$ & Mean \pm SD & $\mathbf{N}$ & Mean \pm SD & & \\
\hline Caliber (mm) & 28 & $5.75 \pm 0.62$ & 28 & $6.45 \pm 0.60$ & $<0.0001$ & 0.0002 \\
\hline PSV (cm/sec) & 28 & $137.50 \pm 34.50$ & 28 & $135.26 \pm 33.81$ & 0.8075 & 0.7297 \\
\hline $\mathrm{RV}(\mathrm{cm} / \mathrm{sec})$ & 28 & $7.25 \pm 6.37$ & 28 & $18.52 \pm 6.16$ & $<0.0001$ & $<0.0001$ \\
\hline $\operatorname{EDV}(\mathrm{cm} / \mathrm{sec})$ & 28 & $16.34 \pm 7.03$ & 28 & $12.64 \pm 5.46$ & 0.0321 & 0.0650 \\
\hline $\mathrm{mV}(\mathrm{cm} / \mathrm{sec})$ & 28 & $38.03 \pm 13.90$ & 28 & $28.32 \pm 9.25$ & 0.0035 & 0.0150 \\
\hline Blood-flow $(\mathrm{cm} / \mathrm{sec})$ & 28 & $1073.1 \pm 831.16$ & 28 & $913.36 \pm 272.87$ & 0.3409 & 0.4781 \\
\hline $\mathrm{PI}$ & 28 & $3.33 \pm 0.75$ & 28 & $4.53 \pm 1.03$ & $<0.0001$ & 0.0002 \\
\hline RI & 28 & $0.88 \pm 0.04$ & 28 & $0.91 \pm 0.03$ & 0.0034 & 0.0141 \\
\hline \multicolumn{7}{|l|}{ IMA } \\
\hline Caliber (mm) & 26 & $2.71 \pm 0.47$ & 24 & $2.79 \pm 0.37$ & 0.4872 & 0.5385 \\
\hline PSV $(\mathrm{cm} / \mathrm{sec})$ & 23 & $72.27 \pm 27.23$ & 23 & $93.81 \pm 25.73$ & 0.0084 & 0.0044 \\
\hline $\mathrm{RV}(\mathrm{cm} / \mathrm{sec})$ & 23 & $2.69 \pm 6.10$ & 23 & $17.06 \pm 5.75$ & $<0.0001$ & $<0.0001$ \\
\hline $\operatorname{EDV}(\mathrm{cm} / \mathrm{sec})$ & 23 & $7.87 \pm 2.01$ & 23 & $7.95 \pm 2.10$ & 0.8921 & 0.9250 \\
\hline $\mathrm{mV}(\mathrm{cm} / \mathrm{sec})$ & 23 & $17.83 \pm 5.33$ & 23 & $14.75 \pm 5.08$ & 0.0514 & 0.3938 \\
\hline Blood-flow $(\mathrm{cm} / \mathrm{sec})$ & 23 & $106.70 \pm 47.99$ & 20 & $84.00 \pm 30.13$ & 0.0676 & 0.3056 \\
\hline $\mathrm{PI}$ & 23 & $3.54 \pm 0.95$ & 23 & $6.08 \pm 1.53$ & $<0.0001$ & $<0.0001$ \\
\hline RI & 23 & $0.88 \pm 0.04$ & 23 & $0.91 \pm 0.03$ & 0.0132 & 0.0205 \\
\hline
\end{tabular}

SMA=superior mesentheric artery, IMA=inferior mesentheric artery, PSV=Peak Systolic Velocity, RV=Reverse Velocity, EDV=End-Diastolic Velocity, $\mathrm{mV}=$ Mean Velocity, $\mathrm{Pl}=$ Pulsatility Index, RI=Resistive Index.

Conclusion: this preliminary study shows, for the first time, the presence of a significant reduction of RV, $\mathrm{PI}$ and $\mathrm{RI}$ in the intestinal arteries of SSc patients when compared to $\mathrm{HC}$. These data show an increased stiffness of the gastrointestinal arterial wall, in agreement with the typical SSc vasculopathy. A larger cohort is needed to confirm the results and explore the possible relationship with other clinical features of the disease.

REFERENCES:

[1] Sjogren, RW. Gastrointestinal features of scleroderma. Curr Opin Rheumatol 1996;8:569-75.

Disclosure of Interests: None declared

DOI: 10.1136/annrheumdis-2021-eular.647

\section{OP0177 PRESENCE AND SEVERITY OF DIGITAL OCCLUSIVE ARTERIAL DISEASE PREDICTS DIGITAL ISCHEMIC COMPLICATIONS IN SYSTEMIC SCLEROSIS}

Y. Radwan ${ }^{1,2}$, T. Gunderson ${ }^{3}$, C. S. Crowson ${ }^{2,3}$, D. Liedl ${ }^{4}$, K. J. Warrington ${ }^{2}$, P. Wennberg ${ }^{4}$, A. Makol ${ }^{2}{ }^{1}$ Michigan State University, Department of Internal Medicine, Lansing, United States of America; ${ }^{2}$ Mayo Clinic, Division of Rheumatology, Rochester, United States of America; ${ }^{3}$ Mayo Clinic, Health Sciences Research, Rochester, United States of America; ${ }^{4}$ Mayo Clinic, Department of Cardiovascular Disease, Rochester, United States of America

Background: Vasculopathy is a key feature of systemic sclerosis (SSc), manifesting clinically as Raynaud's phenomenon (RP) with or without digital ischemia. Laser doppler flowmetry (LDF) with thermal challenge is a safe, noninvasive and reproducible technique to detect digital occlusive arterial disease (DOAD) with a high sensitivity and specificity of $>90 \%$ (1).

Objectives: To study the prevalence and clinical correlates of DOAD assessed by LDF in patients with SSc referred for evaluation of RP at a tertiary referral center. Methods: Medical records of all patients with SSc meeting ACR/EULAR 2013 classification criteria that underwent LDF between Jan 2001-Dec 2018 at our institution were retrospectively reviewed to abstract the presence or absence of DOAD. The presence of DOAD on LDF was confirmed if pre- and post-warming skin blood flow was $\leq 206$ arbitrary units. Severity of DOAD was assessed based on number of digits involved. Risk factors associated with presence of DOAD in SSc, and correlation between presence and severity of DOAD with digital ischemic complications were studied.

Results: 304 patients with SSc (mean age $57.1 \pm 3.3$ y, 81\% females, 93\% Caucasians) underwent LDF during the study period. Median time between SSc diagnosis and performing LDF was 12.9 months. Majority of patients with SSc had limited cutaneous SSc (ICSSc) (79.6\%) and 64.1\% had a positive SSc specific antibody. On LDF with thermal challenge, presence of DOAD was noted in $243(79.9 \%)$ patients, of whom $78.6 \%$ had IcSSc, $42.4 \%$ had a centromere antibody (Ab), $17.3 \%$ had a Scl-70 Ab, 53.5\% had interstitial lung disease, $36.6 \%$ had pulmonary arterial hypertension, and $73.3 \%$ had gastrointestinal dysmotility (GID). Of 159 patients with DOAD who also had a nailfold capillaroscopy, $70.4 \%$ had abnormalities. Large vessel occlusive disease was significantly higher in patients with DOAD in comparison to those without DOAD (29.2\% vs $16.4 \%$; $p$ : 0.04$)$. After adjusting for age and sex, GID (OR: $2.73[95 \% \mathrm{Cl} 1.52-4.92])$ and telangiectasia (OR: 2.83 [95\%Cl 1.23-6.40]) were significantly associated with DOAD. Digital ischemic complications among patients with SSc with DOAD were significantly higher than among those without DOAD $(79.8 \%$ vs $41.0 \%$ had digital ulcers, $53.9 \%$ vs $26.2 \%$ had pitting/scars, $31.3 \%$ vs $8.2 \%$ had gangrene/amputation; $p<0.001$ ). (Figure 1) Increasing severity of DOAD was associated with a statistically significantly higher incidence of digital ischemic complications as presented in Table 1.

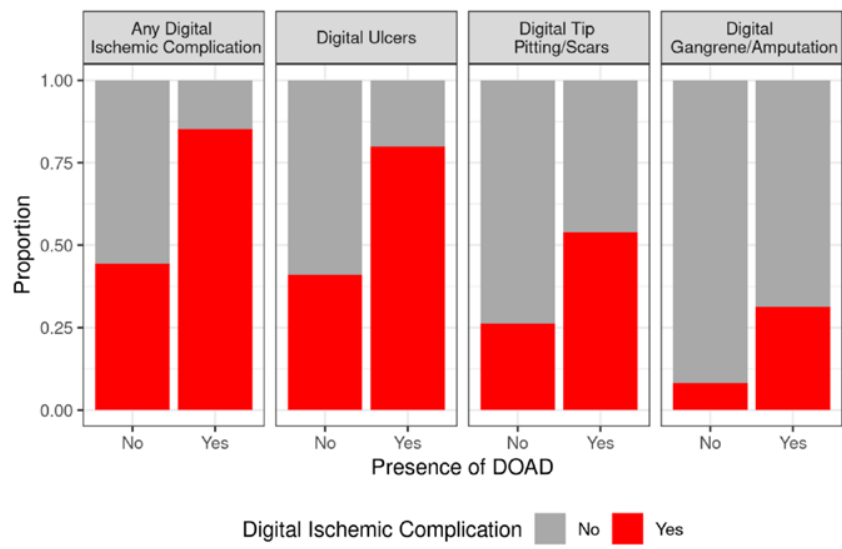

Figure 1. Correlation between the presence of digital occlusive arterial disease (DOAD) and digital ischemic complications in systemic sclerosis

Table 1. Logistic regression models for association of digital ischemic complications and severity of digital occlusive arterial disease

\begin{tabular}{lccc}
\hline Digital Involvement & Odds Ratio (OR) & & \\
Complication & Reflects "digits vs. 0" & OR & Cl 95\% \\
\hline Digital Ulcer & Unit Increase & 1.28 & $1.19-1.39$ \\
& $\mathbf{1 - 2}$ & 2.11 & $0.927-4.92$ \\
& $\mathbf{3 - 7}$ & 5.57 & $2.84-11.2$ \\
Digital Tip Pitting/Scars & $\mathbf{8 - 1 0}$ & 10.9 & $4.98-25.4$ \\
& Unit Increase & 1.17 & $1.10-1.26$ \\
& $\mathbf{1 - 2}$ & 1.92 & $0.803-4.61$ \\
& $\mathbf{3 - 7}$ & 2.62 & $1.35-5.28$ \\
Digital Gangrene/Amputation & $\mathbf{8 - 1 0}$ & 5.45 & $2.72-11.4$ \\
& Unit Increase & 1.26 & $1.16-1.37$ \\
& $\mathbf{1 - 2}$ & 1.36 & $0.317-5.48$ \\
& $\mathbf{3 - 7}$ & 4.10 & $1.62-12.6$ \\
Any Digital Involvement & $\mathbf{8 - 1 0}$ & 9.05 & $3.60-27.7$ \\
& Unit Increase & 1.35 & $1.24-1.49$ \\
& $\mathbf{1 - 2}$ & 2.98 & $1.27-7.30$ \\
& $\mathbf{3 - 7}$ & 6.16 & $3.08-12.7$ \\
& $\mathbf{8 - 1 0}$ & 18.5 & $7.46-53.2$ \\
\hline
\end{tabular}

Conclusion: This is the largest single center study to describe the prevalence and predictors of DOAD on LDF in a well-defined cohort of patients with SSc. The high prevalence of DOAD on LDF noted in SSc-RP make it a valuable tool no only for evaluation of vasculopathy in SSc but also to distinguish it from Primary RP. The presence and severity of DOAD strongly correlates with digital ischemic complications and can be used as a guide to counsel patients and determine the aggressiveness of therapeutic interventions. Our study underscores the significance of LDF as a reliable non-invasive modality to detect DOAD and a prognostic tool to identify patients at highest risk of digital ischemic complications. REFERENCES:

[1] Mahe G et al. J Vasc Surg. 2014 Apr;59(4):1051-1057.e1

Disclosure of Interests: None declared

DOI: 10.1136/annrheumdis-2021-eular.924

\section{Rheumatoid arthritis - prognosis, predictors and outcome}

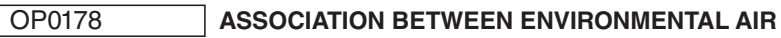 POLLUTION AND RHEUMATOID ARTHRITIS FLARES}

G. Adami ${ }^{1}$, A. Fassio ${ }^{1}$, O. Viapiana ${ }^{1}$, G. Orsolini ${ }^{1}$, E. Bertoldo ${ }^{1}$, A. Giollo ${ }^{1}$,

D. Gatti ${ }^{1}$, M. Rossini ${ }^{1} .{ }^{1}$ University of Verona, Rheumatology Unit, Verona, Italy

Background: Environmental air pollution has been linked to the pathogenesis of Rheumatoid Arthritis (RA). Nevertheless, evidence linking higher concentrations of air pollutants with the risk of RA reactivations is missing.

Objectives: The objective of the present study was to determine the association between RA flares and air pollution.

Methods: We collected longitudinal data of patients affected by RA and of the daily concentration of air pollutants in the Verona area. We designed a case-crossover study. In case-crossover studies, instead of obtaining information from two groups (cases and controls), the exposure information is obtained comparing two different periods of time in the same group of patients followed longitudinally. We compared the exposure to pollutants in the 30-day and 60-day periods preceding an arthritic flare referent to the 30-day and 60-day preceding a low-disease activity visit. Flare was defined as an increase in DAS28-CRP of $>1.2$ points with current DAS28-CRP $\geq 3.2$ (OMERACT definition). 
Results: 888 patients with RA with 3,396 follow-up visits were included in the study. 13,636 daily air pollution records were retrieved. We found an exposure-response relationship between the concentration of air pollutants and the risk of having abnormal CRP levels (Figure 1). Patients exposed to greater concentrations of air pollutants were at higher risk of having CRP levels $\geq 5 \mathrm{mg} / \mathrm{L}$. Patients exposed to PM10 concentrations $\geq 50 \mu \mathrm{g} / \mathrm{m} 3$ had a $70 \%$ higher risk of having CRP levels $\geq 5 \mathrm{mg} / \mathrm{L}$ (OR 1.696 95\% Cl, 1.245-2.311). Among RA patients, 440 patients (49.5\%) had at least 2 follow-up visits with a difference in DAS28-CRP of more than 1.2 points (with current DAS28-CRP $\geq 3.2$ ), serving as our sample for the case-crossover study. Concentrations of $\mathrm{CO}, \mathrm{NO}$, NO2, NOx, PM10, PM2.5 and $\mathrm{O} 3$ were higher in the 60-day period preceding a flare (Table 1). Sensitivity analyses considering geometric mean and cumulative concentrations yielded similar results (data not shown). Remarkably, we found that the cumulative exposure to NO2 in the 60 days preceding a flare was approximately $500 \mu \mathrm{g} / \mathrm{m} 3$ higher than the low disease activity visit, an exposure that equates to approximately to 200 passively smoked cigarettes (3.5 cigarettes per day on a 60-day period).

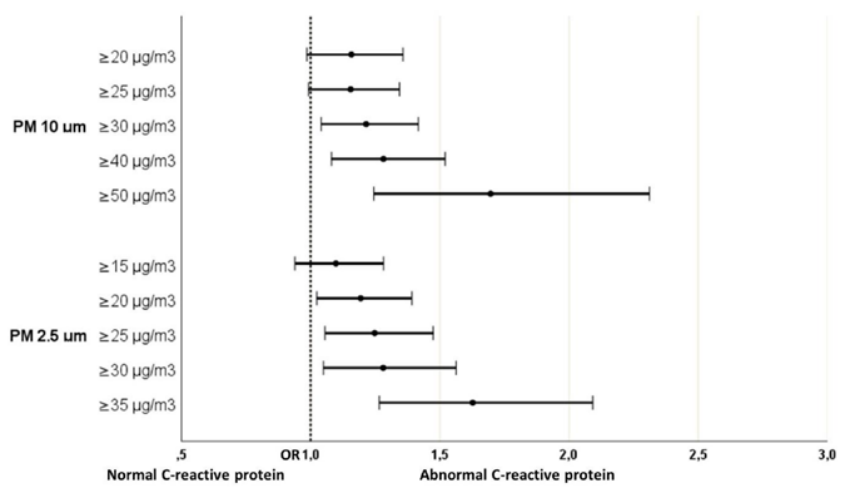

Figure 1. Odds of having abnormal CRP serum levels $(\geq 5 \mathrm{mg} / \mathrm{L})$ at different exposures of PM10 and PM2.5 (mean concentration in the 60 days before assessment)

Table 1. Case-crossover study. Mean concentrations (mean and Area Under the Curve) of air pollutants in the 60 days before low-disease activity visit and flare visit (DAS28-CRP difference >1.2)

\begin{tabular}{|c|c|c|c|c|}
\hline Pollutant & & $\begin{array}{l}\text { Control period (low disease } \\
\text { activity, } n=440 \text { ) }\end{array}$ & $\begin{array}{l}\text { Hazard period } \\
\text { (flare, } n=440 \text { ) }\end{array}$ & $\begin{array}{c}p \\
\text { value }\end{array}$ \\
\hline \multirow[t]{2}{*}{$\mathrm{CO} \mu \mathrm{g} / \mathrm{m}^{3}$} & Mean & 0.38 & 0.42 & 0.001 \\
\hline & AUC & 22.00 & 24.53 & 0.001 \\
\hline \multirow{2}{*}{$\mathrm{NO} \mu \mathrm{g} / \mathrm{m}^{3}$} & Mean & 19.23 & 24.11 & 0.002 \\
\hline & AUC & $1,120.53$ & $1,403.88$ & 0.002 \\
\hline \multirow{2}{*}{$\mathrm{NO}_{2} \mu \mathrm{g} / \mathrm{m}^{3}$} & Mean & 30.91 & 32.44 & 0.042 \\
\hline & AUC & $1,800.96$ & $1,892.05$ & 0.040 \\
\hline \multirow[t]{2}{*}{$\mathrm{NO}_{x} \mu \mathrm{g} / \mathrm{m}^{3}$} & Mean & 60.34 & 69.35 & 0.004 \\
\hline & AUC & $3,515.77$ & $4,041.06$ & 0.004 \\
\hline \multirow[t]{2}{*}{$\mathrm{PM} 10 \mu \mathrm{g} / \mathrm{m}^{3}$} & Mean & 31.21 & 33.65 & 0.011 \\
\hline & AUC & $1,789.22$ & $1,942.52$ & 0.005 \\
\hline \multirow{2}{*}{$\mathrm{O}_{3} \mu \mathrm{g} / \mathrm{m}^{3}$} & Mean & 31.08 & 33.79 & 0.002 \\
\hline & AUC & $1,776.37$ & $1,934.35$ & 0.001 \\
\hline \multirow[t]{2}{*}{ PM2. $5 \mu \mathrm{g} / \mathrm{m}^{3}$} & Mean & 23.08 & 24.74 & 0.018 \\
\hline & AUC & $1,272.61$ & $1,403.60$ & $<0.001$ \\
\hline
\end{tabular}

Conclusion: We found a striking association between air pollution and RA disease severity and reactivations in a cohort of patients followed over a 5-year period. The exposure to high levels of air pollutants was associated with increased CRP levels and a higher risk of experiencing a flare of arthritis. This excessive risk was evident at very low levels of exposure, even below the proposed threshold for the protection of human health. Our study has important and direct consequences. In order to reduce the burden of RA, public and environmental health policy makers should aim to diminish gaseous and PM emissions to a larger extent as currently recommended. Disclosure of Interests: None declared

DOI: 10.1136/annrheumdis-2021-eular.216

\section{OP0179 DISCONTINUATION RATE OF TOFACITINIB IS SIMILAR WHEN COMPARED TO TNF INHIBITORS IN RHEUMATOID ARTHRITIS PATIENTS: POOLED DATA FROM TWO RHEUMATOID ARTHRITIS REGISTRIES IN CANADA}

M. Movahedi ${ }^{1}$, D. Choquette ${ }^{2}$, L. Coupal ${ }^{2}$, A. Cesta ${ }^{1}$, X. LI ${ }^{1}$, E. Keystone ${ }^{3}$, C. Bombardier ${ }^{1}$ on behalf of OBRI and RHUMADATA Investigators. ${ }^{1} \mathrm{UHN}$, Toronto General Hospital Research Institute, Toronto, Canada; ${ }^{2}$ Institut de Rhumatologie de Montréal, RHUMADATA, Montreal, Canada; ${ }^{3}$ University of Toronto, Medicine, Toronto, Canada

Background: Tofacitinib (TOFA) is an oral, small molecule drug used for rheumatoid arthritis (RA) treatment as the first or an alternative option to biologic disease- modifying antirheumatic drugs (bDMARDs), including tumor necrosis factor inhibitors (TNFi). The similarity in retention of TNFi and TOFA was previously reported separately by the Ontario Best Practices Research Initiative (OBRI) and the Quebec cohort RHUMADATA ${ }^{\circledR}$.

Objectives: To increase the study power, we propose to evaluate the discontinuation rate (due to any reason) of TNFi compared to TOFA, using pooled data from both these registries.

Methods: RA patients enrolled in the OBRI and RHUMADATA initiating their TOFA or TNFi between $1^{\text {st }}$ June 2014 (TOFA approval date in Canada) and $31^{\text {st }}$ Dec 2019 were included. Time to discontinuation was assessed using adjusted Kaplan-Meier (KM) survival and Cox regression models. To deal with confounding by indication, we estimated propensity scores for covariates with a standard difference greater than 0.1 . Models were then adjusted using stratification and inverse probability of treatment weight (IPTW) methods. Multiple imputation (Imputation by Chained Equation method, $\mathrm{N}=20$ ) was used to deal with missing data for covariates at treatment initiation.

Results: A total of 1318 patients initiated TNFi $(n=825)$ or TOFA $(n=493)$ with mean (SD) disease duration of 8.9 (9.3) and 13.0 (10.1) years, respectively. In the TNF group, $78.8 \%$ were female and mean age (SD) at treatment initiation was 57.6 (12.6) years. In the TOFA group, $84.6 \%$ were female and mean (SD) age at treatment initiation was 59.5 (11.5) years. The TNFi group was less likely to have prior biologic use $(33.9 \%)$ than the TOFA group $(66.9 \%)$. At treatment initiation, the mean (SD) CDAI was significantly $(p<0.05)$ lower in the TNFi group [20.0 (11.7)] compared to the TOFA group [22.1(12.4)]. Physical function measured by HAQ-DI was also significantly lower $(p<0.05)$ in the TNFi compared to the TOFA group (1.2 vs.1.3).

Over a mean follow-up of 23.2 months, discontinuation was reported in 309 $(37.5 \%)$ and $182(36.9 \%)$ of all TNFi and TOFA patients, respectively. After adjusting for propensity score deciles across 20 imputed datasets, there was no significant difference in discontinuation between treatment groups (adjusted HRs: $0.96,95 \% \mathrm{Cl}: 0.78-1.18 ; \mathrm{p}=0.69$ ). The results were similar for two propensity adjustment methods. Figure 1 shows IPTW adjusted KM survival curves comparing discontinuation rates in patients treated with TNFi and TOFA.

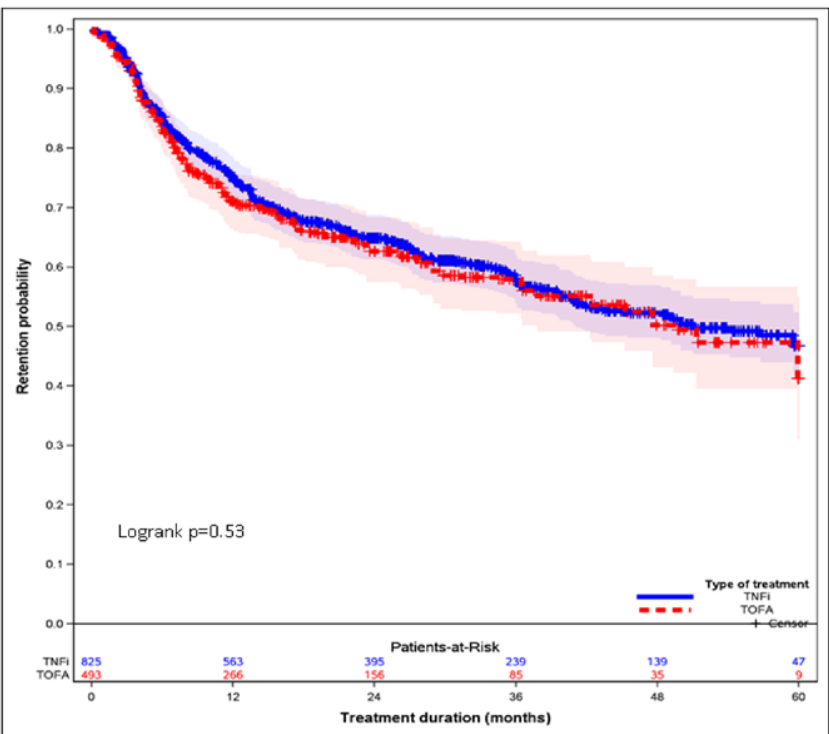

Figure 1. Note: Propensity Score Weighted (IPTW) Survival Curves was performed using one imputed dataset

Conclusion: In this pooled real -world data study, we found that TNFi and TOFA retention is similar in patients with RA. In the next step we will analysis the data for specific reasons of dicontinutaion. We will also repeat analysis comparing discontinuation in the first users versus those after one or more biologic failure. Disclosure of Interests: Mohammad Movahedi: None declared, Denis Choquette Grant/research support from: Rhumadata ${ }^{\circledR}$ is supported by unrestricted grants from Abbvie Canada, Amgen Canada, Eli Lilly Canada, Novartis Canada, Pfizer Canada, Sandoz Canada and Sanofi Canada., Louis Coupal: None declared Angela Cesta: None declared, Xiuying Li: None declared, Edward Keystone Grant/research support from: Amgen, Merck, Pfizer Pharmaceuticals, PuraPharm. Speaker Honoraria Agreements: AbbVie, Amgen, Bristol-Myers Squibb Company, Celltrion, Myriad Autoimmune, F. Hoffmann-La Roche Inc, Gilead, Janssen Inc, Lilly Pharmaceuticals, Merck, Pfizer Pharmaceuticals, Sandoz, Sanofi-Genzyme, Samsung Bioepsis. Consulting Agreements/Advisory Board Membership: AbbVie, Amgen, Bristol-Myers Squibb Company, Celltrion, Myriad Autoimmune, F. Hoffmann-La Roche Inc, Gilead, Janssen Inc, Lilly Pharmaceuticals, Merck, Pfizer Pharmaceuticals, Sandoz, Sanofi-Genzyme, Samsung Bioepsis, Claire Bombardier Grant/research support from: OBRI was funded by peer reviewed grants from CIHR (Canadian Institute for Health Research), Ontario Ministry of Health and Long-Term Care (MOHLTC), Canadian Arthritis Network (CAN) and unrestricted 